Errata 601

\title{
ERRATA
}

\section{A PROBABLE APPROACH TO THE GEOMETRIZATION OF INTERACTION}

\author{
[MOD. PHY. LETT. A, Vol. 3, No. 10 (1988) 1025-1031]
}

LEV BOGDAN IVANOVITCH

In the Contents Page and running heads, the author's name should read B. I. Lev, and not L. B. Ivanovitch. 